\title{
ANALISIS KONDISI INTERNAL-EKSTERNAL PENGEMUDI MOBIL TANGKI DALAM PENINGKATAN SAFETY DRIVING PT ELNUSA PETROFIN DI KOTA PAREPARE
}

\section{Analysis of Internal-External Condition of Drivers of Tank Cars in Improving Safety Driving of PT Elnusa Petrofin in the City of Parepare}

\author{
Elmayanti, Andi Nuddin, Makhrajani Majid \\ Program Studi Kesehatan Masyarakat Fakultas Ilmu Kesehatan Universitas Muhammadiyah Parepare \\ (emaayb22@gmail.com)
}

\begin{abstract}
ABSTRAK
Safety driving merupakan bagian dari budaya keselamatan jalan (road safety culture) yang melihat bagaimana tindakan aman seseorang dalam mengemudi. Terdapat dua faktor yang berhubungan dengan safety driving, yaitu faktor internal dan faktor eksternal. Tujuan penelitian ini untuk menunjukkan faktor apa saja yang berpengaruh terhadap safety driving. Jenis penelitian ini menggunakan metode deskriptif analitik dengan pendekatan Cross Sectional Study. Populasi dalam penelitian ini pengemudi mobil tangki yang bekerja di PT Elnusa Petrofin Parepare. Pengambilan sampel dengan menggunakan metode random sampling sebanyak 64 orang. Analisis data menggunakan uji Chi Square. Ho ditolak jika nilai $p<0.05$ dan Ha diterima jika nilai $p>0.05$. Hasil penelitian menunjukkan bahwa dari enam variabel yang diukur pengaruhnya dengan safety driving, lima diantaranya menunjukkan pengaruh yang positif yaitu masa kerja $=0.008$, keikutsertaan diklat $=$ 0.015 , peran rekan kerja $=0.000$, kondisi jalan $=0.000$, dan kondisi cuaca $=0.000$ yang berpengaruh terhadap safety driving, sedangkan satu variabel lainnya tidak menunjukkan pengaruh terhadap safety driving dengan $p$ value 0.231 . Oleh karena itu disarankan kepada pengemudi untuk mengikuti diklat safety driving dalam meningkatkan kemampuan berkendaraan.
\end{abstract}

Kata Kunci : Safety driving, pengemudi mobil tangki

\begin{abstract}
Safety driving is a part of a road safety culture that saw how the person's safe action in driving. There are two factors related to safety driving, internal factor and external factor. The purpose of this study was to show what factors influence driving safety. This type of research uses a descriptive analytic method with a Cross-Sectional Study approach. The population in this study were tank car drivers who worked at PT Elnusa Petrofin Parepare. Sampling using a random sampling method of 64 people. Data analysis using Chi-Square test. Ho was rejected if the value was $p<0.05$ and Ha was accepted if the value of $p>0.05$. The results showed that of the six variables measured by driving safety, five of them showed a positive effect, namely work period $=0.008$, training participation $=$ 0.015 , the role of coworkers $=0.000$, road conditions $=0.000$, and weather conditions $=0.000$ which affected safety driving, while one other variable does not show an effect on safety driving with $p$ value 0.231. Therefore, it was recommended for drivers to take part in safety driving training in improving their driving ability.
\end{abstract}

Keywords: Safety driving, tanker driver 


\section{PENDAHULUAN}

Mengemudi merupakan suatu perilaku yang membutuhkan proses kognisi yang digunakan sebagai pengambil keputusan dalam berkendaraan, membutuhkan kematangan emosi yang baik agar tidak terjadi hal-hal yang tidak menyenangkan saat di jalan raya, hal tersebut juga membutuhkan perhatian dan konsentrasi. Perilaku mengemudi juga tidak terlepas dari prinsip keselamatan berkendaraanan (safety driving). Pengertian dari safety driving ialah dasar perilaku mengemudi yang lebih memperhatikan keselamatan khususnya bagi pengemudi itu sendiri dan umumnya pada penumpang. Safety driving didesain untuk meningkatkan kesadaran pengemudi terhadap segala kemungkinan yang tejadi selama mengemudi.

Safety driving dipengaruhi oleh beberapa faktor antara lain faktor internal seperti usia, pendidikan, lama bekerja, pengetahuan, keikutsertaan pelatihan, peran atasan, peran rekan kerja, dan faktor eksternal seperti kondisi jalan dan kondisi cuaca. ${ }^{1}$

Data dari World Health Organization (WHO) menunjukkan setidaknya 1,2 juta warga dunia tewas setiap tahun akibat kecelakaan lalu lintas. Indonesia berada di posisi keenam terbesar dari sisi jumlah korban kecelakaan yang meninggal dunia dan menurut laporan Global Status Report on Road Safety 2015, jumlah korban tewas yang dilaporkan di Indonesia sekitar 26 ribu jiwa. ${ }^{2}$
Menurut data kecelakaan lalu lintas Ditlantas Polda Sulawesi Selatan melalui Badan Pusat Statistik (BPS), di Sulawesi Selatan sendiri jumlah orang yang mengalami kecelakaan lalu lintas terus meningkat dari tahun ke tahun. Di tahun 2014 kejadian kecelakaan lalu lintas mencapai 4.435 dengan jumlah kerugian materi sebesar Rp.15.417.531, ${ }^{3}$ kemudian di tahun 2015 kasus kecelakaannya meningkat menjadi 4.834 dengan jumlah kerugian materi sebesar Rp.13.399.270, ${ }^{4}$ dan pada tahun 2016 kasus kecelakaan lalu lintas sudah mencapai 6.030 dengan jumlah kerugian materi sebesar 12.365.305..$^{5}$

Mengingat banyaknya kerugian yang ditimbulkan oleh kecelakaan jalan, maka kita perlu membangun dan mengembangkan budaya keselamatan jalan (Road Safety Culture). Budaya dapat mempengaruhi bagaimana seseorang bersikap dan bertindak. Budaya yang baik akan memberikan hasil yang optimal, sebaliknya budaya yang tidak kondusif tidak akan memberikan hasil yang optimal dengan keselamatan jalan (road safety), seseorang yang telah berkondisi dengan budaya disiplin akan bersikap patuh dengan peraturan dan etika di perjalanan, begitu juga sebaliknya

Ketidakdisiplinan seseorang pada saat mengemudi dapat menyebabkan kecelakaan. Dari sekian banyak kecelakaan yang terjadi di Indonesia, sebagian besar $(90,3 \%)$ disebabkan oleh faktor manusia. Lebih jauh lagi, dari 
90,3\% kecelakaan yang disebabkan oleh faktor manusia tersebut, sebesar $86,8 \%$ disebabkan oleh kesalahan pengemudi. ${ }^{6}$

PT Elnusa Pertrofin merupakan salah satu anak perusahaan PT Pertamina (Persero) yang menangani bisnis distribusi bahan bakar minyak (BBM). PT Elnusa Petrofin Parepare hingga saat ini memiliki awak mobil tangki (AMT) sebanyak 172, adapun area distribusinya adalah mulai dari wilayah Parepare dan sekitarnya, Enrekang, Barru, Soppeng, Bone, Pinrang, Sengkang, Tator, Sidrap, dan wilayah Sulawesi Barat. Aktivitas pendistribusian ini tentu saja memiliki risiko keselamatan yang akan dihadapi perusahaan pada saat kegiatan operasional dijalankan.

Kecelakaan merupakan salah satu risiko keselamatan tersebut. Menurut data yang didapat adapun jumlah insiden kecelakaan mobil tangki di PT Elnusa Petrofin Parepare dari tahun 2013-2017 yaitu sebanyak 27 kasus. Dan angka tersebut merupakan angka yang tinggi dan cukup menjadi masalah yang serius bagi pihak perusahaan, baik dari segi biaya maupun waktu kerja yang hilang.

Oleh karena itu, penelitian mengenai “Analisis Kondisi Internal-Eksternal Pengemudi Mobil Tangki Dalam Peningkatan Safety Driving Pt Elnusa Petrofin Kota Parepare" dapat menjadi upaya untuk mengetahui hal-hal yang berkaitan dengan penyebab kecelakaan di perusahaan tersebut. Selain itu penelitian ini juga dapat melihat gambaran safety driving pada pengemudi.

\section{BAHAN DAN METODE}

Metode yang digunakan dalam penelitian ini adalah metode deskriptif analitik dengan pendekatan cross sectional. Populasi dalam penelitian ini adalah seluruh pengemudi mobil tangki yang berjumlah 172 orang yang bekerja di PT. Elnusa Petrofin Parepare. Variabel independen dalam penelitian ini adalah umur pengemudi, masa kerja, keikutsertaan diklat, peran rekan kerja, kondisi jalan dan kondisi cuaca sedangkan variabel dependennya adalah safety driving.

Pengumpulan data diperoleh dengan dua cara, yakni data primer (wawancara langsung kepada responden yang menjadi sampel) dan data sekunder berupa data data kecelakaan dan jumlah pengemudi. Instrument dalam penelitian ini menggunakan kuesioner yang akan disebar kepada para responden.

\section{HASIL}

Hasil penelitian pada Tabel 1 menunjukkan bahwa mayoritas pengemudi berada pada kategori umur sedang (31-42 tahun) yakni sebanyak 26 orang (40.6\%) dan minoritas berada pada kategori umur tua (4350) tahun yakni sebanyak 18 orang (28.1\%). Menurut masa kerja, rata-rata pengemudi berada pada masa kerja baru yaitu sebanyak 39 orang $(60.9 \%)$, pengemudi dengan masa kerja sedang sebanyak 17 orang (26.6\%) dan pengemudi dengan masa kerja lama yaitu sebanyak 8 orang (12.5\%). Sedangkan jumlah pengemudi yang pernah mengikuti diklat 
safety driving yaitu sebanyak 40 orang dengan mayoritas kadang-kadang sebanyak 34 orang (53.1\%), dan jumlah pengemudi yang tidak pernah mengikuti diklat safety driving yakni sebanyak 24 orang (37.5\%). Untuk safety driving didapat bahwa jumlah pengemudi yang berperilaku positif mengenai safety driving yaitu sebanyak 15 orang (23.4)\%, berperilaku netral sebanyak 30 orang (46.9\%) dan pengemudi yang berperilaku negatif mengenai safety driving yaitu sebanyak 19 orang (29.7\%). Untuk peran rekan kerja didapat bahwa sebanyak 19 pengemudi (29.7\%) memiliki peran rekan kerja yang sangat mendukung mengenai safety driving, 22 pengemudi (34.4\%) dengan peran rekan kerja yang cukup mendukung dan sebanyak 23 pengemudi (35.9\%) dengan peran rekan kerja yang kurang mendukung mengenai safety driving. Untuk kondisi jalan didapat bahwa jumlah pengemudi yang berperilaku positif ketika mengalami kondisi jalan yang buruk pada saat mengemudi yaitu sebanyak 19 orang (29.7\%), berperilaku netral sebanyak 28 orang (43.8\%) dan jumlah pengemudi yang berperilaku negatif sebanyak 17 orang (26.6\%). Terakhir untuk kondisi cuaca didapat bahwa jumlah pengemudi yang berperilaku positif ketika mengalami kondisi cuaca yang buruk pada saat mengemudi sebanyak 12 pengemudi (18.8\%), berperilaku netral sebanyak 32 orang (50.0\%) dan jumlah responden yang berperilaku negatif sebanyak 20 orang $(31.3 \%)$.
Hasil penelitian pada Tabel 2 menggambarkan pengaruh umur pengemudi mobil tangki terhadap safety driving PT Elnusa Petrofin di Kota Parepare. Berdasarkan tabel terlihat bahwa dari 20 pengemudi yang berada kategori umur muda (18-30 tahun) terdapat 5 orang $(30.0 \%)$ yang memiliki safety driving positif, 6 orang (30.0\%) memiliki safety driving yang netral, 8 orang $(40.0 \%)$ memiliki safety driving yang negatif. Pengemudi yang berada pada kategori umur sedang (31-42 tahun) yaitu sebanyak 26 orang diantaranya 6 orang $(23.1 \%)$ memiliki safety driving yang positif, 10 orang $(38.5 \%)$ memiliki safety driving yang netral, 10 orang (38.5\%) memiliki safety driving yang negatif. Sedangkan pengemudi yang berada pada kategori umur tua (43-55) tahun yaitu sebanyak 18 orang diantaranya 10 orang (55.6\%) memiliki safety driving yang positif, 3 orang (16.7\%) memiliki safety driving yang netral, 5 orang $(27.8 \%)$ memiliki safety driving yang negatif. Hasil analisis dengan menggunakan analisis C-Square diperoleh tidak ada pengaruh umur pengemudi mobil tangki terhadap safety driving. $(\mathrm{p}=0,231)$.

Hasil penelitian pada Tabel 3 menggambarkan pengaruh masa kerja pengemudi mobil tangki terhadap safety driving PT Elnusa Petrofin di Kota Parepare. Berdasarkan tabel terlihat bahwa terdapat 39 pengemudi dengan masa kerja baru (0-2 tahun) diantaranya 7 orang (17.9\%) yang memiliki safety driving positif, 15 orang 
(38.5\%) yang memiliki safety driving netral, 17 orang (43.6\%) memiliki safety driving yang negatif. Pengemudi dengan masa kerja sedang (3-8 tahun) yaitu sebanyak 17 orang diantaranya 9 orang (52.9\%) memiliki safety driving yang positif, 4 orang (23.5\%) memiliki safety driving yang netral, 4 orang (23.5\%) memiliki safety driving yang negatif. Sedangkan Pengemudi dengan masa kerja lama ( $\geq 9$ tahun) yaitu sebanyak 8 orang diantaranya 6 orang $(75.0 \%)$ memiliki safety driving yang positif, dan 2 orang (25.0\%) memiliki safety driving yang negatif. Hasil analisis dengan menggunakan analisis $C$ Square diperoleh ada pengaruh masa kerja pengemudi mobil tangki terhadap safety driving. $(\mathrm{p}=0,008)$.

Hasil penelitian pada Tabel 4 menggambarkan pengaruh keikutsertaan diklat pengemudi mobil tangki terhadap safety driving PT Elnusa Petrofin di Kota Parepare. Berdasarkan tabel terlihat bahwa dari 12 pengemudi yang sering $(\geq 3$ kali) mengikuti diklat safety driving diantaranya 7 orang $(58.3 \%)$ yang memiliki safety driving positif, 2 orang (16.7\%) yang memiliki safety driving netral, 3 orang (25.0\%) memiliki safety driving yang negatif. Pengemudi yang kadang-kadang (1-2 kali) mengikuti diklat yaitu sebanyak 28 orang diantaranya 2 orang (42.9\%) memiliki safety driving yang positif, 10 orang (35.7\%) memiliki safety driving yang netral, 6 orang (21.4\%) memiliki safety driving yang negatif. Sedangkan pengemudi yang tidak pernah mengikuti diklat safety driving yaitu sebanyak 24 orang diantaranya 3 orang $(12.5 \%)$ memiliki safety driving yang positif, 3 orang (29.2\%) memiliki safety driving yang netral dan 14 orang (58.3\%) memiliki safety driving yang negatif. Hasil analisis dengan menggunakan analisis $C$ Square diperoleh ada pengaruh keikutsertaan diklat pengemudi mobil tangki terhadap safety driving. $(\mathrm{p}=0,015)$.

Hasil penelitian pada Tabel 5 menggambarkan pengaruh peran rekan kerja pengemudi mobil tangki terhadap safety driving PT Elnusa Petrofin di Kota Parepare. Berdasarkan tabel terlihat bahwa dari 19 pengemudi dengan peran kerja yang sangat mendukung terdapat 15 orang (78.9\%) yang memiliki safety driving positif dan 5 orang (21.1\%) memiliki safety driving yang netral. Pengemudi dengan peran rekan kerja cukup mendukung yaitu sebanyak 22 orang diantaranya 5 orang $(22.7 \%)$ memiliki safety driving yang positif, 10 orang (45.7\%) memiliki safety driving yang netral, 7 orang (31.8\%) memiliki safety driving yang negatif. Sedangkan pengemudi dengan peran rekan kerja kurang mendukung yaitu sebanyak 23 orang diantaranya 2 orang $(8.7 \%)$ memiliki safety driving yang positif, 5 orang (21.7\%) memiliki safety driving yang netral, 16 orang 
(69.6\%) memiliki safety driving yang negatif.

Hasil analisis dengan menggunakan analisis $C$-Square diperoleh ada pengaruh peran rekan kerja pengemudi mobil tangki terhadap safety driving. $(\mathrm{p}=0,000)$.

Hasil penelitian pada Tabel 6 menggambarkan pengaruh perilaku pengemudi mobil tangki pada kondisi jalan tertentu terhadap safety driving PT Elnusa Petrofin di Kota Parepare. Berdasarkan tabel terlihat bahwa dari 19 pengemudi yang berperilaku positif ketika mengalami kondisi jalan yang buruk pada saat mengemudi diantaranya 15 orang $(78.9 \%)$ yang memiliki safety driving positif, 2 orang (10.5\%) yang memiliki safety driving netral, 2 orang $(10.5 \%)$ memiliki safety driving yang negatif. Pengemudi yang berperilaku netral sebanyak 28 responden diantaranya 7 orang $(25.0 \%)$ memiliki safety driving yang positif, 11 orang (39.3\%) memiliki safety driving yang netral, 10 orang (35.7\%) memiliki safety driving yang negatif. Sedangkan pengemudi yang berperilaku negatif sebanyak 17 orang diantaranya 6 orang (35.3\%) memiliki safety driving yang netral, dan 11 orang (64.7\%) memiliki safety driving yang negatif. Hasil analisis dengan menggunakan analisis $C$ Square diperoleh ada pengaruh kondisi jalan terhadap safety driving. $(\mathrm{p}=0,000)$.

Hasil penelitian pada Tabel 6 menggambarkan pengaruh perilaku pengemudi mobil tangki pada kondisi cuaca tertentu terhadap safety driving PT Elnusa
Petrofin di Kota Parepare. Berdasarkan tabel terlihat bahwa dari 12 pengemudi yang berperilaku positif ketika mengalami kondisi cuaca yang buruk pada saat mengemudi diantaranya 10 orang $(83.3 \%)$ yang memiliki safety driving positif, 1 orang (8.3\%) yang memiliki safety driving netral, 1 orang $(8.3 \%)$ memiliki safety driving yang negatif. Pengemudi yang berperilaku netral sebanyak 32 responden diantaranya 12 orang $(37.5 \%)$ memiliki safety driving yang positif, 12 orang (8.3\%) memiliki safety driving yang netral, 8 orang (25.0\%) memiliki safety driving yang negatif. Sedangkan pengemudi yang berperilaku negatif sebanyak 20 orang diantaranya 6 orang $(30.0 \%)$ memiliki safety driving yang netral, dan 14 orang (70.0\%) memiliki safety driving yang negatif. Hasil analisis dengan menggunakan analisis $C$ Square diperoleh ada pengaruh kondisi cuacaterhadap safety driving. $(\mathrm{p}=0,000)$.

\section{PEMBAHASAN}

Berdasarkan hasil penelitian didapatkan hasil p-value $0.231 \quad(p>0.05)$, menunjukkan bahwa tidak ada pengaruh umur pengemudi mobil tangki terhadap safety driving. Hasil penelitian ini tidak sesuai dengan teori yang menyatakan bahwa umur seseorang dapat mempengaruhi perilaku seseorang dalam berkendara yang aman, seharusnya jika pengemudi yang berumur di atas 30 tahun lebih matang dan lebih pengalaman dalam berperilaku aman dalam 
berkendara daripada pengemudi yang berumur di bawah 30 tahun. $^{7}$

Menurut asumsi peneliti, hal tersebut dikarenakan walaupun umur merupakan faktor untuk merubah perilaku seseorang, namun masih banyak faktor lain yang bisa menghambat perilaku seseorang seperti pengalaman berkendara, sehingga umur yang matang jika pengalaman mengemudinya masih baru kemungkinan akan mempengaruhi perilaku keselamatan berkendara (safety driving), selain itu juga cenderung kurang memperhatikan resiko dan potensi kecelakaan karena merasa lebih berpengalaman dan sudah terbiasa dalam melakukan pekerjaan tersebut. Selain itu, di PT Elnusa Petrofin Kota Parepare umur pengemudi mobil tangki dibatasi yaitu dari umur 18-55 tahun dimana kelompok umur tersebut termasuk usia produktif dalam bekerja. Usia produktif mempunyai risiko lebih kecil dibanding usia tidak produktif mengalami kecelakaan. Usia tidak produktif akan mengalami penurunan ketajaman penglihatan dan pendengaran serta reaksi yang lambat dibanding usia produktif. Responden dengan usia produktif diharapkan dalam bekerja dapat menghindari kecelakaan yang mungkin terjadi. ${ }^{8}$

$$
\text { Berdasarkan hasil penelitian }
$$
didapatkan hasil p-value 0.008 ( $p<0.05)$, menunjukkan bahwa ada pengaruh masa kerja pengemudi mobil tangki terhadap berpengaruh safety driving. Menurut teori Max Webber yang dikemukakan oleh Ritzer menyatakan bahwa setiap individu akan melakukan suatu tindakan berdasarkan lama kerjanya atau pengalamannya. Jadi semakin lama seseorang melakukan suatu aktivitas maka seseorang tersebut akan semakin mengetahui aktivitas tersebut. ${ }^{6}$

Semakin lama masa kerja pengemudi, semakin tinggi juga pengalaman dan skill atau yang dimiliki untuk mencegah terjadinya kecelakaan lalu lintas pada pengemudi. Pengemudi yang memiliki masa kerja yang sedikit atau pengemudi yang masih baru biasanya masih belum mengetahui secara mendalam seluk beluk berkendara dengan selamat.

Hal ini didukung oleh penelitian sebelumnnya yang dilakukan oleh Firmansyah (2013) yang mengatakan semakin lama seseorang bekerja, semakin banyak pengalaman yang didapatkan dan memiliki kecenderungan untuk bertindak lebih aman dalam berkendara. ${ }^{9}$ Sama halnya dengan penelitian yang dilakukan oleh Prasetya (2016) yang mengatakan bahwa semakin lama pengalaman seseorang dalam mengemudi akan menjadikan seseorang tersebut bertambahnya kemampuan, keterampilan dan pengetahuan dalam berkendara sehingga cenderung akan bertindak aman saat berkendara. ${ }^{10}$

Berdasarkan hasil analisis chi-square menunjukkan bahwa ada pengaruh keikutsertaan diklat terhadap safety driving dengan nilai $(p$-value $=0.015)$. Hasil 
penelitian ini sejalan dengan penelitian Firmansyah (2013) yang menyatakan bahwa ada hubungan antara pelatihan mengemudi dengan perilaku safety driving pada pengemudi mobil pengangkut semen curah di PT. Prima Karya Manunggal dengan nilai signifikansi sebesar $0.049 .{ }^{9}$

Dalam hasil penelitan ini masih ada pengemudi mobil tangki yang berperilaku negatif pada saat mengemudi meskipun telah mengikuti diklat safety driving. Hal ini bisa saja terjadi karena pengemudi mobil tangki tidak menerapkan pengetahuan yang didapatkan ketika mengikuti diklat safety driving dan cenderung berperilaku apatis (acuh) dalam hal safety driving. Namun untuk responden yang telah mengikuti diklat safety driving, sebagian besar sudah berperilaku positif dan netral dalam hal safety driving.

Hasil penelitian ini juga menunjukkan bahwa mayoritas pengemudi mobil tangki yang belum pernah mengikuti diklat berperilaku negatif pada saat mengemudi, namun masih ada pengemudi mobil tangki yang berperilaku positif walaupun belum pernah mengikuti diklat. Hal ini bisa terjadi karena bagi sebagian pengemudi, mengemudi merupakan pekerjaan yang berhubungan dengan keahlian dan konsentrasi, sehingga mengemudi bukan hanyua berkaitan dengan pengetahuan seseorang melainkan lebih kepada cara mengatasi situasi tidak aman yang dihadapi seseorang pada saat mengemudi.
Untuk pengemudi yang berperilaku netral terhadap safety driving, bisa diakatakan sudah berperilaku positif terhadap safety driving tetapi karena faktor perilaku lainnya seperti merokok dan menerima panggilan pada saat mengemudi, sehingga pada saat dilakukan penginputan data nilainya berkurang dan berada pada kategori netral.

Sebaiknya pelatihan atau diklat safety driving perlu dilakukan dan merupakan hal yang wajib diberikan perusahaan secara menyeluruh kepada pengemudi tanpa terkecuali, karena pada dasarnya dengan adanya pelatihan dapat meningkatkan kinerja pengemudi tersebut untuk memiliki kemampuan dan keterampilan dalam mengemudi. Perusahaan dapat mengevaluasi pelaksanaan diklat safety driving yang dilaksanakan oleh pihak penyelenggara agar hasil yang diperoleh dari pelatihan yang telah dilaksanakan dapat meningkatkan kinerja pengemudi secara maksimal. Sehingga akan menciptakan kebiasaan mengendarai yang lebih aman, dan dapat menurunkan angka kecelakaan.

$$
\text { Berdasarkan hasil penelitian }
$$
didapatkan hasil p-value $0.000 \quad(p>0.05)$, menunjukkan bahwa ada pengaruh peran rekan kerja pengemudi mobil tangki terhadap safety driving. Hasil penelitian ini sejalan dengan penelitian oleh Nugroho (2017) yang menyatakan bahwa ada pemgaruh antara peran rekan kerja dengan perilaku safety driving 
pada operator forklit di area kerja Warehouse

PT X Jakarta. ${ }^{11}$

Hasil penelitian ini juga sesuai dengan teori L Green dalam Notoatmodjo (2012) yang menyatakan bahwa peran teman kerja sebagai faktor penguat, yaitu salah satu faktor yang dapat memberikan pengaruh terhadap perilaku seseorang. ${ }^{12}$ Dalam penelitian ini, peran rekan kerja mengenai safety driving ditunjukan dengan adanya respon terhadap perilaku mengemudi rekan seperti pemeriksaan kendaraan sebelum berkendara, keselamatan berkendara, batasan kecepatan berkendara, dan sebagainya.

Hasil wawancara mendalam yang dilakukan dengan pengemudi mobil tangki diketahui bahwa rekan kerja saling mengingatkan, akan tetapi pengemudi mobil tangki juga berpendapat jika masih merasa sungkan jika mengingatkan rekan kerja yang usia dan masa kerjanya lebih lama dibandingkan dengan dirinya. Pengemudi mobil tangki juga sepakat bahwa sesama rekan kerja saling mengingatkan untuk berperilaku aman dalam berkendara karena ingin selamat sampai tujuan dan selamat kembali pulang ke rumah untuk bertemu keluarga. Hal ini juga dikarenakan jumlah besar muatan yang dibawa dan risiko yang selalu menginginkan pengemudi dalam perjalanan.

Perilaku dan perasaan seseorang berkaitan erat, selain itu pengaruh kelompok terasa kuat dalam mengubah perilaku individu. Dengan kata lain kelompok atau dalam hal ini adalah peran rekan kerja seseorang sangat berpengaruh untuk mengubah perilaku seseorang. Oleh karena itu, sebaiknya semakin baik perilaku yang ditularkan pada rekan kerjanya maka semakin baik pula rekan kerja tersebut menerima masukan sehingga akan terjadi perubahan perilaku yang positif pada seseorang.

Berdasarkan hasil penelitian didapatkan hasil p-value $0.000 \quad(p>0.05)$, menunjukkan bahwa ada pengaruh perilaku pengemudin pada kondisi jalan tertentu terhadap safety driving.

Dalam kasus kecelakaan yang pernah terjadi di PT Elnusa Petrofin Parepare adalah kecelakaan karena pengereman mendadak saat menghindari lubang. Kebanyakan orang cenderung untuk menghindari lubang tersebut daripada melewatinya dengan alasan tidak nyaman saat melewati lubang atau takut terjatuh karena melindas lubang tersebut.

Menurut Irwadi dalam Oktarina (2012) apabila dihadapkan pada jalan yang berlubang, segeralah memperlambat kendaraan dengan menutup putaran gas dan kedua rem. Namun pada kenyataannya, pengemudi masih saja ada yang tidak mengurangi kecepatannya sehingga akan melakukan pengereman mendadak saat ingin menghindari lubang. Tindakan tersebut tergolong tindakan yang tidak aman dalam berkendara karena dapat mengakibatkan kecelakaan. ${ }^{6}$ 
Teori tersebut sangat relevan dengan hasil analisis penelitian yang menunjukkan adanya pengaruh yang signifikan antara kondisi jalan dengan safety driving. Oleh karena Kondisi jalan merupakan faktor yang tidak bisa dihindari oleh pengemudi, dibutuhkan keikutsertaan diklat safety driving secara menyeluruh oleh para pengemudi. Selain itu dibutuhkan juga sosialisasi ataupun promosi mengenai safety driving khususnya tentang bagaimana cara berperilaku yang positif ketika dihadapkan pada kondisi jalan yang kurang baik agar pengemudi selalu bertindak aman dalam menjalani pekerjaannya yang selalu dihadapi pada kondisi jalan yang kurang baik.

Berdasarkan hasil penelitian didapatkan hasil $p$-value $0.000 \quad(p>0.05)$, menunjukkan bahwa ada pengaruh perilaku pengemudin pada kondisi cuaca tertentu terhadap safety driving.

Menurut Hadani (2011) di negaranegara tropis seperti Indonesia, faktor cuaca seperti hujan memiliki tingkat potensi tinggi memicu terjadinya kecelakaan, yaitu sebesar $13 \% .^{13}$

Irwadi dalam Oktarina menyatakan hujan yang lebat akan membebani penghapus kaca (wiper), sehingga kaca depan selalu tertutup air. Pandangan ke depan sangat terbatas sehingga kita tidak bisa melihat batasbatas jalan ataupun kendaraan-kendaraan yang lain, itu tandanya kita harus meminggir dan berhenti sampai hujan reda. Namun pada kenyataannya, pengemudi tidak terlalu menghiraukan keadaan saat kondisi hujan, apalagi sampai berhenti menunggu hujan reda. Kemungkinan hal itu disebabkan karena pengemudi sudah merasa terbiasa mengemudi dalam kedaan tersebut dan juga mengejar waktu untuk sampai ke tujuan. Hujan juga mempengaruhi kerja kendaraan seperti jarak pengeremen menjadi lebih jauh, jalan menjadi lebih licin dan jarak pandang menjadi lebih pendek. ${ }^{6}$

Hal ini yang dapat menyebabkan kecelakaan bisa saja terjadi, karena pengemudi tidak selamanya akan bertindak aman dalam kondisi hujan. Selain kondisi hujan, cuaca kabut juga dapat mengganggu perjalanan pengemudi. Kabut disebut juga sebagai awan yang menduduki dataran permukaan tanah. Kabut di jalan menurunkan jarak lihat hingga kurang lebih setengah kilometer.

Hal tersebut bisa menimbulkan kondisi berbahaya ketika menaiki kendaraan. Kondisi cuaca berkabut tidak bisa dicegah dan sering dihadapi pengemudi. Apabila perjalanan tidak dapat ditunda, tindakan yang sebaiknya dilakukan oleh pengemudi adalah mengurangi kecepatan pada saat mengemudi serta memperhatikan jarak kendaraan nya. Namun pada kenyataannya pengemudi tidak selalu waspada saat menghadapi kondisi cuaca berkabut. Teori tersebut sangat relevan dengan hasil analisis penelitian yang menunjukkan adanya hubungan yang signifikan antara kondisi cuaca dengan safety driving. 
Oleh karena kondisi cuaca merupakan faktor yang tidak bisa dihindari oleh pengemudi, dibutuhkan keikutsertaan diklat safety driving secara menyeluruh oleh para pengemudi, khususnya materi mengenai bagaimana cara mengemudi yang aman ketika dihadapkan pada kondisi cuaca buruk. Selain itu dibutuhkan juga sosialisasi ataupun promosi mengenai safety driving secara terus menerus untuk meningkatkan kesadaran dan kewaspadaan agar pengemudi selalu berperilaku possitif maupun bertindak aman dalam menjalani pekerjaannya yang selalu dihadapi pada kodisi cuaca yang kurang baik.

\section{KESIMPULAN DAN SARAN}

Berdasarkan hasil penelitian dari analisis kondisi internal-eksternal pengemudi mobil tangki dalam peningkatan safety driving PT Elnusa Petrofin di Kota Parepare, maka diperoleh kesimpulan bahwa tidak ada

\section{DAFTAR PUSTAKA}

1. Adinugroho N. dkk. Faktor yang Berhubungan dengan Praktik Safety Driving pada Pengemudi Angkutan Kota Jurusan Banyumanik-Johar Kota Semarang. Jurnal Kesehatan Masyarakat. 2014;2(6). [Diakses 7 November 2017].

Availableat:

https://media.neliti.com/media/publication s/18367-ID-faktor-yang-berhubungandengan-praktik-safety-driving-padapengemudi-angkutan-ko.pdf. pengaruh umur pengemudi terhadap safety driving dan ada pengaruh masa kerja, keikutsertaan diklat, peran rekan kerja, kondisi jalan dan kondisi cuaca terhadap safety driving PT Elnusa Petrofin di Kota Parepare. Disarankan Pelaksanaan diklat (pendidikan dan pelatihan) mengenai safety driving pada pengemudi harus diberikan secara menyeluruh. Akan lebih baik apabila pada saat penerimaan pengemudi baru langsung dibekali dengan pemberian diklat safety driving sebelum pengemudi tersebut diberi tugas untuk mengemudi dan perusahaan perlu menyesuaikan materi diklat sesuai dengan kebutuhan yang diperlukan pengemudi mobil tangki serta mengevaluasi pelaksanaan diklat safety driving yang dilaksanakan oleh pihak penyelenggara agar hasil yang diperoleh dari pelatihan yang telah dilaksanakan dapat meningkatkan kinerja pengemudi secara maksimal.

2. WHO. (2015). Global Status Report On Road 2015. [Diakses tangal 25 Maret 2018] Available at: http://www.who.int/violence_injury_preve ntion/road_safety_status/2015/en/.

3. Badan Pusat Statistik. 2015. Sulawesi Selatan Dalam Angka 2015. [Diakses 20 November 2017]. Available at: https://sulsel.bps.go.id/.

4. Badan Pusat Statistik. 2016. Provinsi Sulawesi Selatan Dalam Angka 2016. 
Diakses 25 Maret 2018]. Available at: https://sulsel.bps.go.id/.

5. Badan Pusat Statistik. 2017. Provinsi Sulawesi Selatan Dalam Angka 2017. [Diakses 25 Maret 2018]. Available at: https://sulsel.bps.go.id/.

6. Oktarina, S. Faktor-faktor yang Berhubungan dengan Safety Driving pada Pengemudi Mobil Tangki Terminal BBM Medan Group PT Pertamina (Persero) Labuhan Deli Medan. Skripsi, Universitas Sumatera Utara. 2012. [Diakses 12 Oktober 2017]. Available at: https://id.123dok.com/document/downloa $\mathrm{d} / 4 \mathrm{yr} 3 \mathrm{dl} 7 \mathrm{y} \# \_=$

7. Khakim R. Hubungan Antara Umur, Tingkat Pendidikan, Masa Berkendaraan dan Pengetahuan Sengan Perilaku Safety Driving Pada Pengendara Ojek di kota Semarang. Skripsi, Universitas Muhammadiyah Semarang. 2016. [akses 23 November 2017]. Available at: http://repository.unimus.ac.id/50/1/SKRIP SI\%20FULL\%20TEXT\%20RIZAL\%201. pdf.

8. Yuwono A A. Faktor-faktor yang Berhubungan dengan Perilaku Safety Driving pada Sopir Bus di Terminal Tirtonadi.Jurnal:UniversitasMuhammadiy ah Surakarta. 2017. [Diakses 17 Agustus 2018].Availableat:http://eprints.ums.ac.id/ 54838/1/NASKAH\%20PUBLIKASI.pdf.

9. Firmansyah A. 2013. Faktor yang Berhubungan dengan Perilaku Safety
Driving pada Pengemudi Mobil Pengangkut Semen Curah di PT. Prima Karya

Manunggal (PKM) Kab. Pangkep. Jurnal : Universitas Hasanuddin. 2013. [Diakses 7 November 2017]. Available at: http://repository.unhas.ac.id/bitstream/han dle/123456789/5919/JURNAL.pdf?seque nce $=1$

10. Prasetya, A. Faktor yang Berhubungan dengan Safety Driving pada Pengemudi Bus Ekonomi Trayek Semarang Surabaya di Terminal Terboyo Semarang (Online). 2016:4(3). [Diakses 20 September 2018]. Available at: http://ejournals1.undip.ac.id/index.php /jkm.

11. Nugroho M R. Hubungan Antara Self Control dengan Safety Driving pada pengemudi Bus Akap (Antar Kota Antar Provinsi) Di Kota Solo. Skripsi, Universitas Muhammadiyah Surakarta. 2017. [Diakses 16 November 2017]. Available at: http://eprints.ums.ac.id/50666/

12. Notoatmodjo. Promosi Kesehatan dan Perilaku Kesehatan. Jakarta : Rineka Cipta; 2012.

13. Hadani.CuacaBuruk dapat Mengakibatkan Kecelakaan. 2011. [Diakses 25 September 2018].Availableat:http//www.kompas.com /kompascetak/0997/30/sorotan/978654.htm. 


\section{LAMPIRAN}

Tabel 1. Distribusi Variabel Penelitian terhadap Safety Driving PT Elnusa Petrofin Parepare di Kota Parepare

\begin{tabular}{|c|c|c|}
\hline Variabel & Frekuensi & Persen $(\%)$ \\
\hline \multicolumn{3}{|l|}{ Umur Pengemudi } \\
\hline Muda (18-30 tahun) & 20 & 31.3 \\
\hline Sedang (31-42 tahun) & 26 & 40.6 \\
\hline Tua (43-45 tahun) & 18 & 28.1 \\
\hline Total & 64 & 100.0 \\
\hline \multicolumn{3}{|l|}{ Masa Kerja } \\
\hline Baru (0-2 tahun) & 39 & 60.9 \\
\hline Sedang (3-8 tahun) & 17 & 26.6 \\
\hline Lama ( $\geq 9$ tahun $)$ & 8 & 12.5 \\
\hline Total & 64 & 100.0 \\
\hline \multicolumn{3}{|l|}{ Keikutsertaan Diklat } \\
\hline Sering (3-5 kali) & 12 & 18.8 \\
\hline Kadang-kadang (1-2 kali) & 28 & 43.5 \\
\hline Tidak pernah & 24 & 37.5 \\
\hline Total & 64 & 100.0 \\
\hline \multicolumn{3}{|l|}{ Safety Driving } \\
\hline Positif & 22 & 34.4 \\
\hline Netral & 19 & 29.7 \\
\hline Negatif & 23 & 35.9 \\
\hline Total & 64 & 100.0 \\
\hline \multicolumn{3}{|l|}{ Peran Rekan Kerja } \\
\hline Sangat mendukung & 19 & 29.7 \\
\hline Cukup mendukung & 22 & 34.4 \\
\hline Kurang mendukung & 23 & 35.9 \\
\hline Total & 64 & 100.0 \\
\hline Kondisi Jalan & 100 & 100,0 \\
\hline Positif & 19 & 29.7 \\
\hline Netral & 28 & 43.8 \\
\hline Negatif & 17 & 26.6 \\
\hline Total & 64 & 100.0 \\
\hline \multicolumn{3}{|l|}{ Kondisi Cuaca } \\
\hline Positif & 12 & 18.8 \\
\hline Netral & 32 & 50.0 \\
\hline Negatif & 20 & 31.3 \\
\hline Total & 64 & 100.0 \\
\hline
\end{tabular}


Tabel 2. Pengaruh Umur Pengemudi Mobil Tangki Terhadap Safety Driving PT Elnusa Petrofin di Kota Parepare

\begin{tabular}{|c|c|c|c|c|c|c|c|c|c|}
\hline \multirow{3}{*}{ Umur } & \multicolumn{6}{|c|}{ Safety Driving } & \multirow{2}{*}{\multicolumn{2}{|c|}{ Total }} & \multirow{3}{*}{$P$} \\
\hline & \multicolumn{2}{|c|}{ Positif } & \multicolumn{2}{|c|}{ Netral } & \multicolumn{2}{|c|}{ Negatif } & & & \\
\hline & $\mathrm{n}$ & $\%$ & $\mathrm{n}$ & $\%$ & $\mathrm{n}$ & $\%$ & $\mathrm{~N}$ & $\%$ & \\
\hline Muda & 6 & 30.0 & 6 & 30.0 & 8 & 40.0 & 20 & 100.0 & \\
\hline Sedang & 6 & 38.5 & 10 & 38.5 & 10 & 38.5 & 26 & 100.0 & 0.231 \\
\hline Tua & 10 & 55.6 & 3 & 16.7 & 5 & 27.8 & 18 & 100.0 & \\
\hline Total & 22 & 34.4 & 19 & 29.7 & 23 & 35.9 & 64 & 100.0 & \\
\hline
\end{tabular}

Tabel 3. Pengaruh Masa Kerja Pengemudi Mobil Tangki Terhadap Safety Driving PT Elnusa Petrofin di Kota Parepare

\begin{tabular}{|c|c|c|c|c|c|c|c|c|c|}
\hline \multirow{3}{*}{$\begin{array}{l}\text { Masa } \\
\text { Kerja }\end{array}$} & \multicolumn{6}{|c|}{ Safety Driving } & \multirow{2}{*}{\multicolumn{2}{|c|}{ Total }} & \multirow{3}{*}{$P$} \\
\hline & \multicolumn{2}{|c|}{ Positif } & \multicolumn{2}{|c|}{ Netral } & \multicolumn{2}{|c|}{ Negatif } & & & \\
\hline & $\mathrm{n}$ & $\%$ & $\mathrm{n}$ & $\%$ & $\mathrm{~N}$ & $\%$ & $\mathrm{~N}$ & $\%$ & \\
\hline Baru & 7 & 17.9 & 15 & 38.5 & 17 & 43.6 & 39 & 100.0 & \\
\hline Sedang & 9 & 52.9 & 4 & 23.5 & 4 & 23.5 & 17 & 100.0 & 0.008 \\
\hline Lama & 6 & 75.0 & 0 & 0.0 & 2 & 25.0 & 8 & 100.0 & \\
\hline Total & 22 & 34.4 & 19 & 29.7 & 23 & 35.9 & 64 & 100.0 & \\
\hline
\end{tabular}

Tabel 4. Pengaruh Keikutsertaan Diklat Pengemudi Mobil Tangki Terhadap Safety Driving PT Elnusa Petrofin di Kota Parepare

\begin{tabular}{|c|c|c|c|c|c|c|c|c|c|}
\hline \multirow{3}{*}{$\begin{array}{l}\text { Keikutsertaan } \\
\text { Diklat }\end{array}$} & \multicolumn{6}{|c|}{ Safety Driving } & \multirow{2}{*}{\multicolumn{2}{|c|}{ Total }} & \multirow{3}{*}{$P$} \\
\hline & \multicolumn{2}{|c|}{ Positif } & \multicolumn{2}{|c|}{ Netral } & \multicolumn{2}{|c|}{ Negatif } & & & \\
\hline & $\mathrm{n}$ & $\%$ & $\mathrm{n}$ & $\%$ & $\mathrm{n}$ & $\%$ & $\mathrm{~N}$ & $\%$ & \\
\hline Sering & 7 & 58.3 & 2 & 16.7 & 3 & 25.0 & 12 & 100.0 & \\
\hline Kadang-kadang & 2 & 42.9 & 10 & 35.7 & 6 & 21.4 & 28 & 100.0 & 0.015 \\
\hline Tidak Pernah & 3 & 12.5 & 3 & 29.2 & 14 & 58.3 & 24 & 100.0 & \\
\hline Total & 22 & 34.4 & 19 & 29.7 & 23 & 35.9 & 64 & 100.0 & \\
\hline
\end{tabular}


Tabel 5. Pengaruh Peran Rekan Kerja Pengemudi Mobil Tangki Terhadap Safety Driving PT Elnusa Petrofin di Kota Parepare

\begin{tabular}{|c|c|c|c|c|c|c|c|c|c|}
\hline \multirow{3}{*}{$\begin{array}{c}\text { Peran Rekan } \\
\text { Kerja }\end{array}$} & \multicolumn{6}{|c|}{ Safety Driving } & \multirow{2}{*}{\multicolumn{2}{|c|}{ Total }} & \multirow{3}{*}{$P$} \\
\hline & \multicolumn{2}{|c|}{ Positif } & \multicolumn{2}{|c|}{ Netral } & \multicolumn{2}{|c|}{ Negatif } & & & \\
\hline & $\mathrm{n}$ & $\%$ & $\mathrm{n}$ & $\%$ & $\mathrm{n}$ & $\%$ & $\mathrm{~N}$ & $\%$ & \\
\hline $\begin{array}{l}\text { Sangat } \\
\text { mendukung }\end{array}$ & 15 & 78.9 & 4 & 21.1 & 0 & 0.00 & 19 & 100.0 & \\
\hline $\begin{array}{l}\text { Cukup } \\
\text { mendukung }\end{array}$ & 5 & 22.7 & 10 & 45.5 & 7 & 31.8 & 22 & 100.0 & 0.000 \\
\hline $\begin{array}{l}\text { Kurang } \\
\text { mendukung }\end{array}$ & 2 & 8.7 & 5 & 21.7 & 16 & 69.6 & 23 & 100.0 & \\
\hline Total & 22 & 34.4 & 19 & 29.7 & 23 & 35.9 & 64 & 100.0 & \\
\hline
\end{tabular}

Tabel 7. Pengaruh Perilaku Pengemudi Pada Kondisi Jalan Tertentu Terhadap Safety Driving PT Elnusa Petrofin di Kota Parepare

\begin{tabular}{|c|c|c|c|c|c|c|c|c|c|}
\hline \multirow{3}{*}{ Perilaku } & \multicolumn{6}{|c|}{ Safety Driving } & \multirow{2}{*}{\multicolumn{2}{|c|}{ Total }} & \multirow{3}{*}{$P$} \\
\hline & \multicolumn{2}{|c|}{ Positif } & \multicolumn{2}{|c|}{ Netral } & \multicolumn{2}{|c|}{ Negatif } & & & \\
\hline & $\mathrm{n}$ & $\%$ & $\mathrm{n}$ & $\%$ & $\mathrm{n}$ & $\%$ & $\mathrm{~N}$ & $\%$ & \\
\hline Positif & 15 & 78.9 & 2 & 10.5 & 2 & 10.5 & 19 & 100.0 & \\
\hline Netral & 7 & 25.0 & 11 & 39.3 & 10 & 35.7 & 28 & 100.0 & 0.000 \\
\hline Negatif & 0 & 0.0 & 6 & 35.3 & 11 & 64.7 & 17 & 100.0 & \\
\hline Total & 22 & 34.4 & 19 & 29.7 & 23 & 35.9 & 64 & 100.0 & \\
\hline
\end{tabular}

Tabel 8. Pengaruh Perilaku Pengemudi Pada Kondisi Cuaca Tertentu Terhadap Safety Driving PT Elnusa Petrofin di Kota Parepare

\begin{tabular}{|c|c|c|c|c|c|c|c|c|c|}
\hline \multirow{3}{*}{ Perilaku } & \multicolumn{6}{|c|}{ Safety Driving } & \multirow{2}{*}{\multicolumn{2}{|c|}{ Total }} & \multirow{3}{*}{$P$} \\
\hline & \multicolumn{2}{|c|}{ Positif } & \multicolumn{2}{|c|}{ Netral } & \multicolumn{2}{|c|}{ Negatif } & & & \\
\hline & $\mathrm{n}$ & $\%$ & $\mathrm{n}$ & $\%$ & $\mathrm{n}$ & $\%$ & $\mathrm{~N}$ & $\%$ & \\
\hline Positif & 10 & 83.3 & 1 & 8.3 & 1 & 8.3 & 12 & 100.0 & \\
\hline Netral & 12 & 37.5 & 12 & 8.3 & 8 & 25.0 & 32 & 100.0 & 0.000 \\
\hline Negatif & 0 & 0.0 & 6 & 30.0 & 14 & 70.0 & 20 & 100.0 & \\
\hline Total & 22 & 34,4 & 19 & 29,7 & 23 & 35,9 & 64 & 100.0 & \\
\hline
\end{tabular}

